\title{
Protecting buildings against feral pigeons
}

\author{
Daniel Haag-Wackernagel • Ila Geigenfeind
}

Received: 24 April 2008 /Revised: 20 May 2008/Accepted: 21 May 2008 /Published online: 17 June 2008

(C) Springer-Verlag 2008

\begin{abstract}
Feral pigeons (Columba livia, Gmelin 1789) cause different problems for building owners when using structures for daytime perching, sleeping, and breeding. Problems include fouling of building facades and pavements, transmission of allergens and pathogenic microorganisms, and infestations with ectoparasites emanating from breeding sites. Owners are primarily interested in keeping away unwanted pigeons from their property. Pest control companies offer different deterrent systems, of widely varying efficacy, for proofing buildings against feral pigeons. A better solution is avoiding attractive structures during building design or subsequent alterations of existing structures used by feral pigeons. With our study, we elaborate the relevant structural data to help to maintain a building free of pigeons. We performed experiments with free ranging feral pigeons in a feral pigeon loft in the City of Basel, Switzerland. The maximum outlet width a pigeon is not able to pass through is $4 \mathrm{~cm}$; the respective outlet height is $5 \mathrm{~cm}$ and a pigeon-safe square opening is not larger than $6 \times 6 \mathrm{~cm}$. The maximum ledge width a pigeon is not able to sit on is $4 \mathrm{~cm}$. The pigeon-safe angle of inclination for smooth construction materials (tinplate, glass, plastics) is $25^{\circ}$, for medium rough materials (wood, plane concrete) $35^{\circ}$, and for rough materials (sandstone, rough concrete) at least $50^{\circ}$. Additionally, we studied the
\end{abstract}

\footnotetext{
Communicated by W. Lutz

D. Haag-Wackernagel $(\bowtie) \cdot$ I. Geigenfeind

Department of Biomedicine, Institute of Anatomy,

University of Basel,

Pestalozzistrasse 20,

4056 Basel, Switzerland

e-mail: daniel.haag@unibas.ch

I. Geigenfeind

e-mail: ila.geigenfeind@unibas.ch
}

behavioral strategies used by feral pigeons to surmount our experimental constructional restrictions, ledge width, and ledge inclinations. Our data provide the essential data to prevent feral pigeons from using building structures.

Keywords Columba livia Behavior - Building structures . Deterrent systems $\cdot$ Constructional restrictions

\section{Introduction}

Feral pigeons are descendants of the domesticated form of the wild rock dove (Columba livia, Gmelin 1789). After World War II, feral pigeon populations increased worldwide in most larger cities due to feeding by pigeon enthusiasts, food discarded by humans, accidental food spillage, and on a lesser scale by seasonally occurring natural food (Simms 1979; Haag-Wackernagel 1995). Regular food supply allows pigeons extra time for breeding, so that some individuals are able to breed throughout the year (Murton et al. 1972; Johnston and Janiga 1995). Pigeons living in urban areas have expanded their originally granivorous diet to the extent that feral pigeons are now omnivorous (Haag 1984).

Large feral pigeon populations cause various problems. Their vocalization may cause hysteric reactions (Carle 1959) and insomnia in sensitive persons when occupying buildings (Wormuth 1994). Excessive population density activates density-dependent regulation mechanisms (Haag 1991a).

An individual pigeon produces around $12 \mathrm{~kg}$ of excreta yearly (Kösters et al. 1991) that fouls breeding sites, house facades, monuments, pavements, sidewalks, and other public areas and is able to deface and deteriorate calcareous stone (Del Monte and Sabbioni 1986; Dell'Omo 1996).

Feral pigeons living close to humans can present a health risk. Ectoparasites can migrate from breeding sites into 
human living space when they lose their natural hosts and infest humans causing traumatic experiences to the persons concerned (Haag-Wackernagel 2005). Feral pigeons harbor at least 110 different human pathogenic microorganisms (Haag-Wackernagel and Moch 2004). In fact, of these human pathogens harbored by feral pigeons, up to the present, only seven caused a total of 230 human infections worldwide, 13 with a fatal course (Haag-Wackernagel and Moch 2004; Haag-Wackernagel 2006). Recently, the risk of pigeon breeders' disease (allergic alveolitis) due to exposure to feral pigeons emerged and so far nine cases, of which one was fatal, have been reported worldwide since 2000 (Haag-Wackernagel 2006).

Many cases of parasitic infestations and disease transmissions could be traced back to feral pigeons breeding at house facades or in attics. Facing these problems, house owners and city authorities want to avoid pigeon infestations. Pest control companies offer a wide range of deterrent systems but these vary in efficacy and are costly and often difficult to install and maintain. Conspicuous systems can detract from the architectural impression and many systems confer only limited or transient protection. Experiments with free-living feral pigeons demonstrated that highly motivated individuals are able to surmount almost every deterrent system (Haag-Wackernagel 2000).

Pigeons are able to use very small spaces to build their nests and can squeeze through tight passages to reach their favorite sites (Fig. 1) and they are able to sit on steeply inclined and small ledges. The exclusion of pigeons from buildings is the best option to solve this problem. However, in many cases aesthetic or technical needs do not allow complete sealing. Feral pigeons can be discouraged from roosting on ledges by installing sloping surfaces over the flat surface or downsizing openings to the extent preventing a feral pigeon from passing. This can be as simple as a board or metal sheet installed with a steep angle. Problems could be more efficiently prevented by incorporating

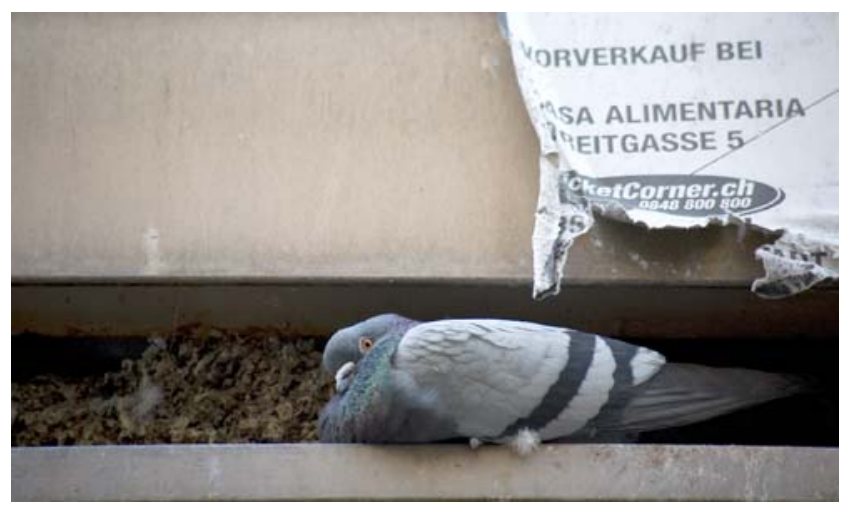

Fig. 1 Feral pigeons are able to use small hollows within building facades as breeding sites deterrent features into building design at the planning stage. This requires knowledge of the physical features that will exclude pigeons.

In the literature, only few and more general data on structural measures have been published and data on the minimal dimensions of openings feral pigeons can squeeze through are completely missing. In this paper, we describe experiments undertaken to determine the minimum apertures that pigeons can enter when they are highly motivated to do so and the maximum slopes that they can tolerate. These data provide sound guidance for the avoidance of pigeon infestations in building design.

\section{Materials and methods}

The pigeons used for this study were free-living feral pigeons breeding in nest boxes in the loft of the St. Matthew Church in Basel, Switzerland. The loft lies above the nave of the church and has a floor space of $30 \mathrm{~m}^{2}$. Around 120 feral pigeons are residents in this loft. Experiments were performed under natural conditions, the birds obtaining all their food and water from their normal resources in the city. The loft is cleaned every 14 days and in the event of the occurrence of ectoparasites (red blood mite Dermanyssus gallinae or pigeon tick Argas reflexus) the nests are treated with an acaricide (Vapona pest strips with dichlorvos). The 39 breeding boxes are $48 \mathrm{~cm}$ wide, $28 \mathrm{~cm}$ high, and $41 \mathrm{~cm}$ deep and can be closed from outside the loft to catch breeding birds.

Body masses of 206 feral pigeons were recorded during dissections performed for an earlier study (Haag 1984). Morphological data were recorded with 20 adult breeding feral pigeons caught in the loft. With a ruler, we measured the widest part of the chest with closed wings (max chest width), the widest part of the chest without wings (minimal chest width), and the circumference of the chest with closed wings (maximal chest circumference).

To investigate the minimal area required for a feral pigeon nest, the inner flat part of the nest where the birds are able to lie (minimal nest diameter) and the outer diameter that includes most of the nesting material, preventing the eggs from rolling out (maximal nest diameter), were measured in 16 nests.

The pigeons enter and leave the loft at will. The experiments to investigate the minimal openings were performed at the single entrance to the loft, constructed as a trapdoor of $42 \mathrm{~cm}$ wide $\times 40 \mathrm{~cm}$ high. The trapdoor can be opened and closed by a linkage from outside the loft. In the experimental design, a tunnel of $38.5 \mathrm{~cm}$ high $\times 38.5 \mathrm{~cm}$ wide $\times 60 \mathrm{~cm}$ long was placed in front of the loft entrance for the duration of the experiments (Fig. 2). For 1 month before the experiments started, the pigeons had the 


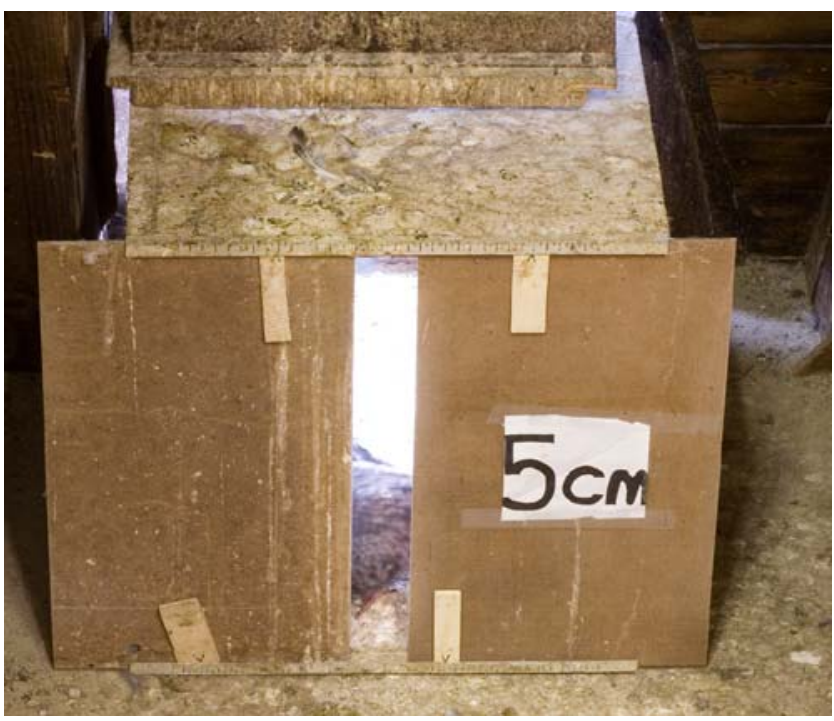

Fig. 2 Experimental design with a tunnel and adjustable wooden boards to test the minimal restriction a feral pigeon is able to pass through. In this experimental design, the width can be varied to the extent that also a highly motivated pigeon is not able to squeeze through the opening

opportunity to habituate to the altered entrance. Pigeons are highly motivated to enter or leave the loft even when obstructed with an experimental reduction of the opening to reach their nesting sites or to leave the loft to forage. During four 4-h intervals, the frequency of pigeons passing through the tunnel without the experimental restriction was recorded twice in the morning between 0800 and $1200 \mathrm{~h}$ and twice in the afternoon between 1400 and $1800 \mathrm{~h}$. To investigate the minimal outlet height and width and the minimum outlet square opening that allowed feral pigeons to squeeze through, a restriction of the outlet was constructed with adjustable wooden boards fixed in tracks that were attached to the inner front opening of the tunnel. A video camera was used to record all pigeons entering and exiting the loft during four 4-h recordings. The openings were restricted in decreasing steps of $1 \mathrm{~cm}$ until no pigeon was recorded successfully negotiating the experimental restriction.

To investigate the minimal ledge width a pigeon can sit on, a nest box not occupied by a breeding pair, and therefore used briefly by different individuals, was observed. During four 4-h intervals recorded with video, the frequency of pigeons staying in the unaltered box was recorded. With an adjustable construction of a vertically erected wooden board $(42.4 \times 26.5 \mathrm{~cm})$, the nest box ledge was decreased in 1-cm steps beginning with an "experimental ledge" of $10 \mathrm{~cm}$ to the width on which no pigeon was able to sit for $>1 \mathrm{~s}$ (Fig. 3).

Inclination tests were performed in nest boxes that were occupied by breeding pairs. The birds were highly

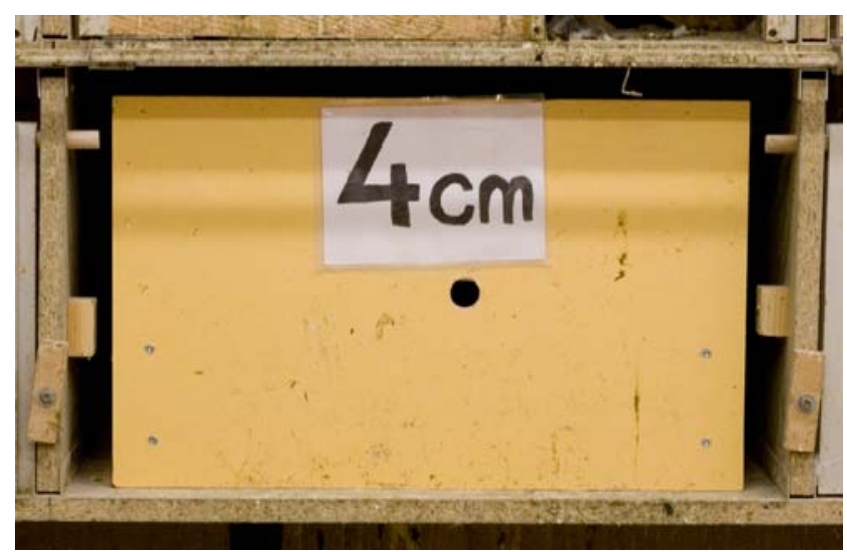

Fig. 3 Experimental design to test the ledge width with a variable holder placed in an unoccupied nest box

motivated to return to their nest and therefore attempted to sit on the test installation even if very uncomfortable. The same method was already successfully used for an earlier study to test pigeon deterrent systems (HaagWackernagel 2000). On an adjustable retainer of $42 \times$ $30 \mathrm{~cm}$, test materials (a tinplate slab, a plywood board, a washed out concrete board, and a ground sandstone slab) of the same size were fixed and then placed in the nest box (Fig. 4). The inclination was increased in steps of $5^{\circ}$ to the angle the pigeon was unable to stay for $>1 \mathrm{~s}$. An inclination was assessed as unusable (negative) when in five different occupied nest boxes no pigeon was able to stay on the test slope for $>1 \mathrm{~s}$.

After each recording interval of all experiments, the restrictions were removed to allow the pigeons to rehabituate to their familiar environment. Video recordings of all experiments were subsequently analyzed on a video recorder. Selected scenes were imported into the video program iMovie on a Macintosh Computer MacPro and analyzed using slow motion and detail screen function.

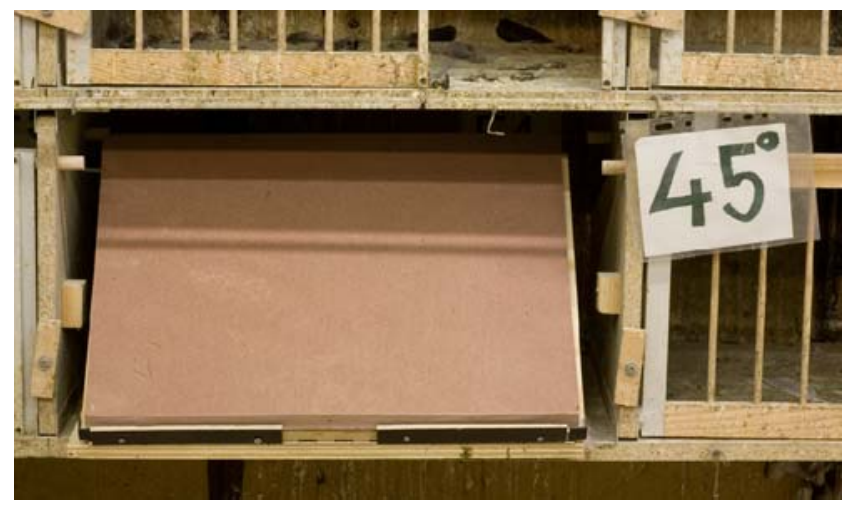

Fig. 4 With a holder fixing the test material, here a sandstone slab, the maximal inclined slope a feral pigeon can sit on was tested 


\section{Results}

Morphological traits

The minimal opening a pigeon can pass through depends on its body dimensions. The most relevant morphological factors are (a) distance between keel of sternum and the thoracic vertebrae of the back and (b) chest width (Fig. 5). The average body mass for adult males in Basel was $345.5 \mathrm{~g}$ (SD 30.5, $n=76$ ) and for females $307.4 \mathrm{~g}$ (SD 35.2, $n=35)$. The average widest part of the chest with closed wings of 20 adult feral pigeons was $8.6 \mathrm{~cm}$ (SD $0.53 \mathrm{~cm}$ ), the widest part of the chest without wings $6.13 \mathrm{~cm}$ (SD $0.41 \mathrm{~cm}$ ), and the circumference with closed wings $25.25 \mathrm{~cm}$ (SD $1.4 \mathrm{~cm}$ ) resulting in a mean chest diameter of $8.04 \mathrm{~cm}$. Theoretically, a pigeon should not be able to squeeze through an opening $<6 \mathrm{~cm}$ as a result of these morphological restrictions (widest chest width).

\section{Nest dimensions}

The 16 measured nests had an average outer diameter of $20.0 \mathrm{~cm}(\mathrm{SD} 5.3 \mathrm{~cm}$ ) and an inner diameter of $10.9 \mathrm{~cm}$ (SD $1.57 \mathrm{~cm}$ ). The inner diameter of $10.9 \mathrm{~cm}$ seems to be the

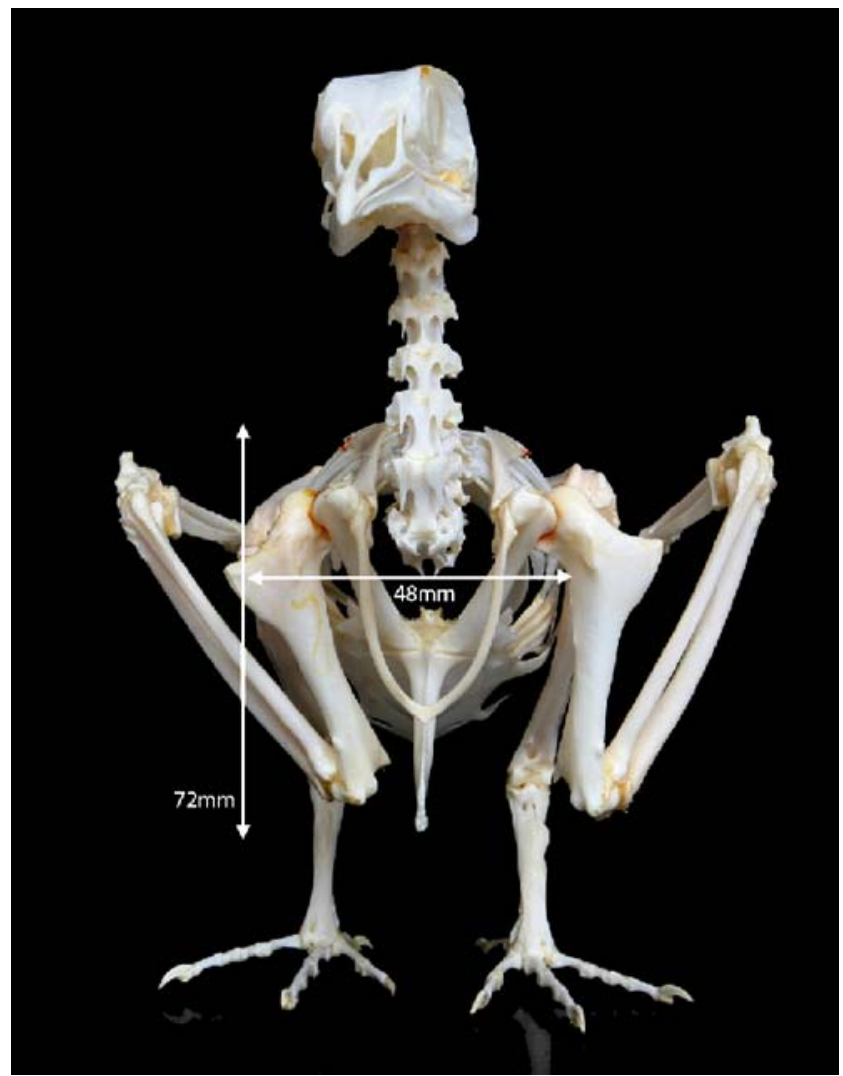

Fig. 5 The skeleton of a pigeon shows the morphological traits relevant for the ability to pass through structural restrictions. Chest width and distance between keel of sternum and the thoracic vertebrae of the back are outlined minimum dimension a feral pigeon needs to perform its normal behavior, including space demanding breeding behaviors such as nest building, molding (while lying down at the nest site, the bird rotates its body in a horizontal plane and often performs scratching movements with the feet on the substratum to build a mold in the nest), and incubation (Fabricius and Jansson 1963; Haag 1991b).

\section{Entrance restriction}

The tunnel without an experimental restriction was passed by an average of 550.3 pigeons per 4 -h interval ( $\min 214$, $\max 944$, SD 375.3). There is no evidence that the tunnel, compared with the normal $42 \times 40-\mathrm{cm}$ trapdoor entrance, had any deterrent effect on the pigeons.

Restriction in width Figure 6 shows the numbers of pigeons that passed the restrictions of $7-4 \mathrm{~cm}$. With a width of $5 \mathrm{~cm}$, only few passages were recorded $(\bar{x} 3$ pigeons per 4 -h interval, $\min 1, \max 9, \mathrm{SD} 4)$. With a restriction of $4 \mathrm{~cm}$, no pigeon was able to pass during four 4-h intervals. Figure 7 shows sketches of a video analysis of a feral pigeon squeezing through a restriction width of $6 \mathrm{~cm}$. The bird had to turn the chest diagonally to attain its smallest chest radius and to position the wings from horizontal to vertical. The optimal position is realized by an angle of $45^{\circ}$ between the vertical of the restriction and the direction of the back to keel axis. This position corresponds to the diagonal of the chest (Fig. 5). Simultaneously, the bird rests upon the elbow (Fig. 7, 3 and 4). After having passed the chest, the body axis is turned back to a horizontal position and the bird slips through the restriction (Fig. 7, 5 and 6).

Restriction in height Figure 8 shows the number of pigeons passing a height restriction from 7 to $5 \mathrm{~cm}$. A height restriction of $7 \mathrm{~cm}$ with an average of 119 pigeons per 4-h interval ( $\min 42, \max 196, \mathrm{SD} 72.8$ ) seemed not to be a problem whereas a $6-\mathrm{cm}$ restriction led to a considerable decrease in passages with an average of 4.5 pigeons per 4-h interval ( $\min 1, \max 11, \mathrm{SD} 4.5)$. With a 5 -cm restriction, no pigeon was able to pass. Video analysis of the behavior revealed a lateral torsion of the chest of $25^{\circ}$ combined with a simultaneous crouching allowing the bird to pass.

Square restriction Figure 9 shows the number of pigeons passing a square restriction with an edge length ranging from 8 to $6 \mathrm{~cm}$. With a square of $8 \times 8 \mathrm{~cm}$, an average of 12.4 pigeons per 4 -h interval $(\min 9, \max 35, \operatorname{SD} 12.4$ ) were able to pass. A square restriction of $7 \times 7 \mathrm{~cm}$ led to a significant decrease in passages $(\bar{x} 4.5, \min 1, \max 11, \mathrm{SD}$ $4.5)$ while a square restriction of $6 \times 6 \mathrm{~cm}$ prevented pigeons from passing. With a square restriction, the pigeons did not 


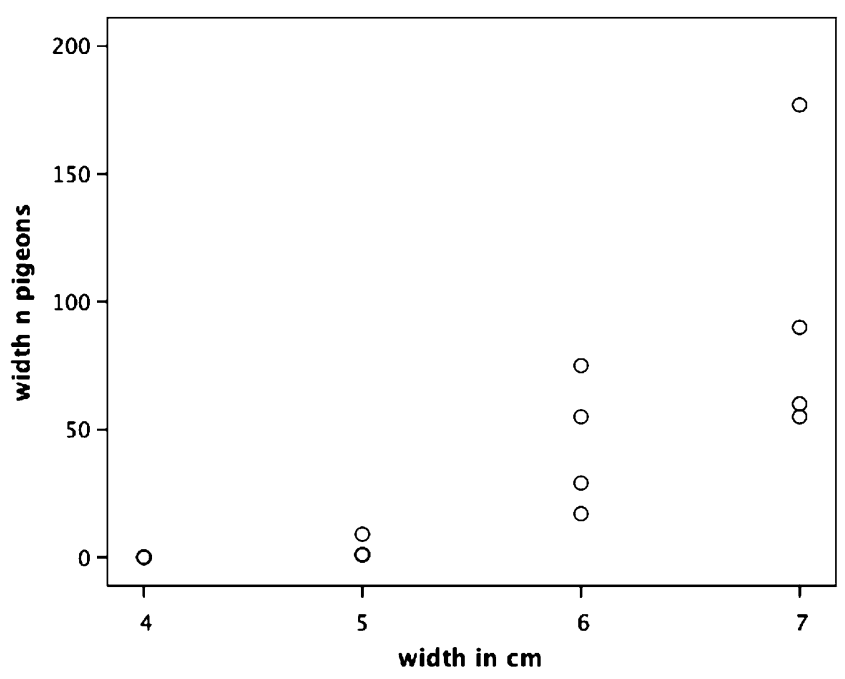

Fig. 6 Number of feral pigeons per 4-h interval that were able to pass a restriction in width

apply special behaviors to fit their body to the experimental restrictions.

\section{Ledge width}

Figure 10 shows the number of pigeons that were able to sit on a variable ledge width of $10-4 \mathrm{~cm}$. A ledge width of $10-6 \mathrm{~cm}$ seemed not to be a problem for a feral pigeon to sit on. On a ledge width of $5 \mathrm{~cm}$, only few pigeons are able to sit ( $\bar{x} 3.25$ pigeons per 4 -h interval, $\min 1, \max 5, \mathrm{SD} 2.06$ ). A ledge is pigeon safe with a width of $4 \mathrm{~cm}$.

\section{Angle of inclination}

Table 1 shows the results of the experiments with inclined slopes of four different construction materials. On an inclined tinplate slab angled at $20^{\circ}$, pigeons were not able to stay for $>1$ s. Plywood and concrete slopes had to be inclined further, with an angle of at least $30^{\circ}$, to prevent feral pigeons from staying. Sandstone, with a rougher surface texture, needed to be inclined at least to $45^{\circ}$ to exclude pigeons.

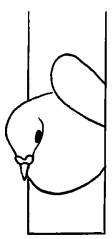

1

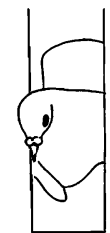

2

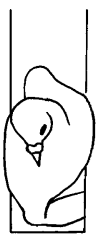

3

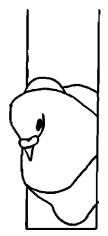

4

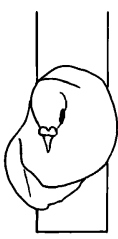

5

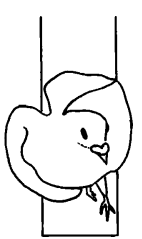

6
Fig. 7 Behavior shown by a feral pigeon to squeeze through a restriction with a restriction width of $6 \mathrm{~cm}$

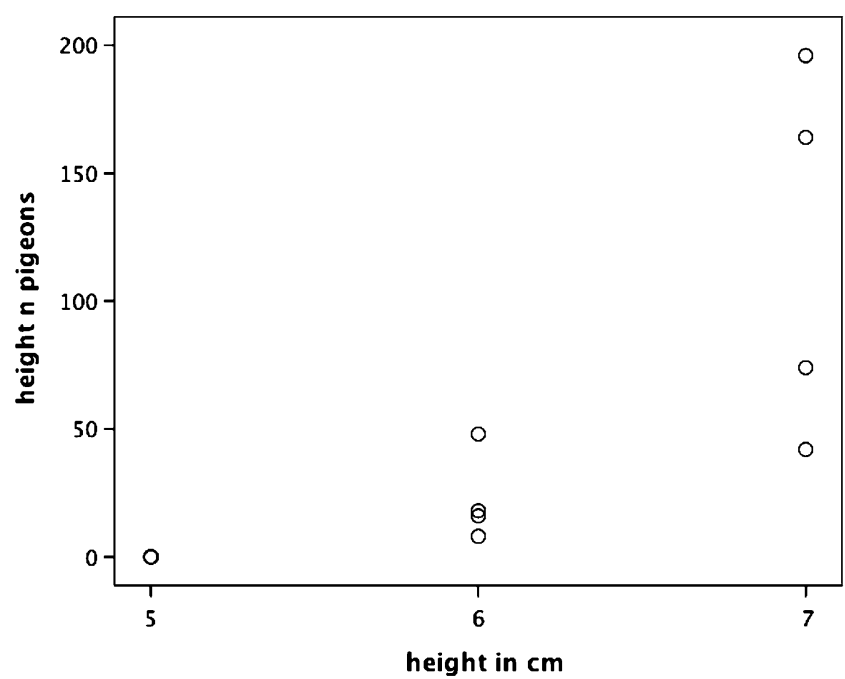

Fig. 8 Number of feral pigeons per 4-h interval that were able to pass a restriction in height

\section{Discussion}

Body size limits a feral pigeon's ability to pass through a structural restriction. The body mass of feral pigeons varies geographically up to $30 \%$ (Johnston and Janiga 1995). The mean body mass of feral pigeons in Basel (males $345.4 \mathrm{~g}$ SD $30.5 \mathrm{~g}$, females $307.4 \mathrm{~g}$ SD $35.2 \mathrm{~g}$ ) lies between large strains from Lawrence, KS, USA (males $358.7 \mathrm{~g}$ SD $38.6 \mathrm{~g}$, females $340.1 \mathrm{~g}$ SD $34.7 \mathrm{~g}$ ) and small Rock-Dove-like strains from Fertilia, Sardinia, Italy (males $289.4 \mathrm{~g} \mathrm{SD}$ $16.8 \mathrm{~g}$, females $242.5 \mathrm{~g}$ SD $17.7 \mathrm{~g}$; Johnston and Janiga 1995). The midrange of the feral pigeons of Basel suggests that our results should be applicable to most other feral pigeon populations.

Any restriction of the tunnel had a strong deterrent effect on the feral pigeons of our experimental loft. This demonstrates that feral pigeons react extremely carefully

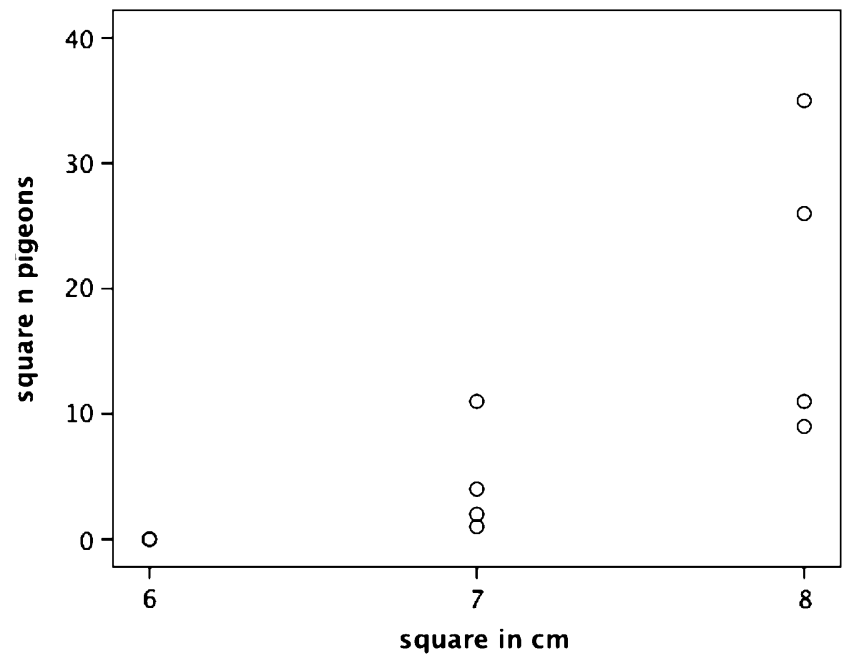

Fig. 9 Number of feral pigeons per 4-h interval that were able to pass a square restriction with an edge length ranging from 8 to $6 \mathrm{~cm}$ 


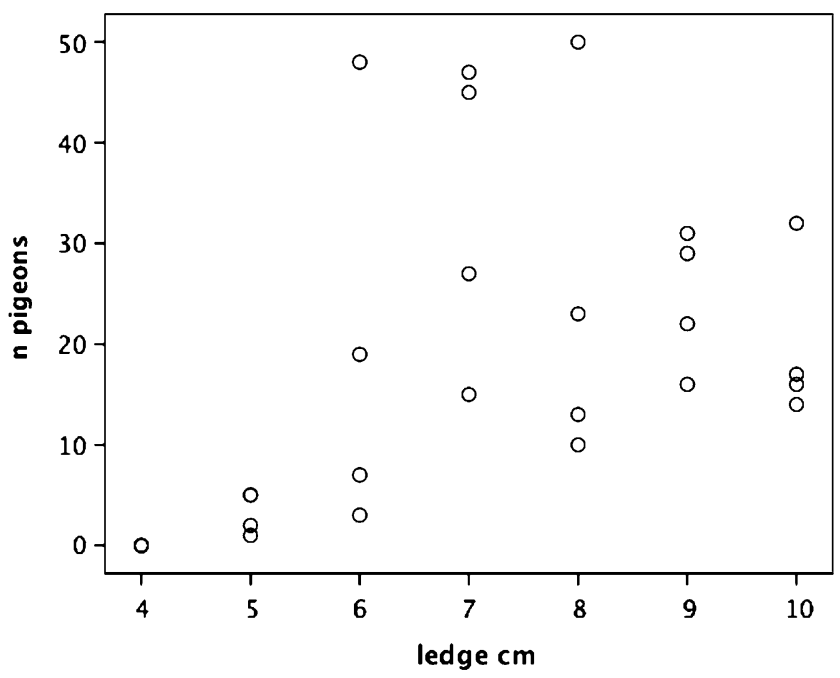

Fig. 10 Number of feral pigeons per 4-h interval that were able to sit on a ledge of restricted width

and shyly towards alterations of their familiar environment, a neophobic reaction. We assume that only birds under a high motivation tried to pass the experimental restrictions, such as breeding individuals that want to reach their nest. We additionally observed that pigeons that did not pass the experimental design waited until the end of the 4-h experiments outside the loft.

Feral pigeons can squeeze through astonishingly narrow restrictions close to the limit determined by their skeletal anatomy. Due to special behavioral strategies, the birds were able to fit the body to extremely narrow restrictions in width by turning the chest diagonally to an angle of $45^{\circ}$ and expanding the body to the vertical axis. Only a 4-cm-wide restriction excluded pigeons. With a horizontal restriction, the bird was unable to lift the wing in the same way to use the smallest chest radius. Therefore, the lateral torsion of the chest was limited to an angle of $25^{\circ}$, leading to a minimum height of $6 \mathrm{~cm}$ to allow passing compared with $5 \mathrm{~cm}$ in a width restriction. A square restriction does not allow lifting

Table 1 Identification of the angle of inclination of a slope a feral pigeon is able to sit on depending on different construction materials

\begin{tabular}{lllll}
\hline Angle of inclination & Tinplate & Plywood & Concrete & Sandstone \\
\hline $15^{\circ}$ & $1^{\text {a }}$ pos & & & \\
$20^{\circ}$ & 5 neg & 1 pos & 1 pos & \\
$25^{\circ}$ & & 1 pos & 1 pos & \\
$30^{\circ}$ & & 5 neg & 5 neg & 1 pos \\
$35^{\circ}$ & & 5 neg & 5 neg & 1 pos \\
$40^{\circ}$ & & & 1 pos \\
$45^{\circ}$ & & & 5 neg \\
\hline
\end{tabular}

${ }^{a}$ Number of experiments performed in an occupied breeding box, pos (positive) $=$ pigeon is able to sit for $>1 \mathrm{~s}$, neg (negative) $=$ pigeon slips off. The italicized part of the table designates the angles of the respective materials a feral pigeon is not able to sit on. the wings to attain a lateral torsion. This led to an increased space demand of at least $7 \times 7 \mathrm{~cm}$. According to their behavioral possibilities, pigeon deterrent dimensions of openings can be achieved with a width of $\leq 4 \mathrm{~cm}$, a height of $\leq 5 \mathrm{~cm}$, and a square restriction of $\leq 6 \times 6 \mathrm{~cm}$.

The ability to sit on a narrow ledge depends on the standing width (distance between the legs) of a feral pigeon in relation to its center of gravity. In our experiments, a 4$\mathrm{cm}$-wide ledge prevented pigeons from sitting on it. This width of $4 \mathrm{~cm}$ is $2 \mathrm{~cm}$ smaller than the single recommended literature value of $6 \mathrm{~cm}$ (Andelt and Burnham 1993).

Artificial restrictions preventing access to buildings for feral pigeons could also have an effect by excluding other city birds using the same sites as, e.g., kestrels. Bats and smaller birds as, e.g., swifts can still use openings that exclude feral pigeons (Thurston 1983).

The few recommendations in the literature indicate angles of inclined slopes for feral pigeons without respect to the texture of the material. Andelt and Burnham (1993) and Kern (2007) recommended angles exceeding $45^{\circ}$, and $>55^{\circ}$ was recommended by the German Landesamt fur Arbeitsschutz (2000). We found that the ability of a feral pigeon to sit on an inclined slope depends on the construction material and on the angle of inclination of the respective materials. Accordingly, the rough and grainy surface of sandstone needs a steeper inclination $\left(45^{\circ}\right)$ than the slippery tinplate $\left(20^{\circ}\right)$ to prevent pigeons from sitting on it. All construction materials experience weathering and seasonal variation in temperature that can lead to erosion and increases the roughness of the surface. Additionally, we observed that pigeons with dirty feet deposited this material, mostly droppings, on the surface of the slope when trying to land. This led to improved foothold over time, allowing pigeons to sit on steeper slopes. Hence, we recommend adding a safety addition of $5^{\circ}$ to our experimental data and to regularly clean smooth inclined surfaces intended to keep pigeons away. Field observations showed that feral pigeons are not able to use ledges with angles $>50^{\circ}$ for more than a few seconds even if the material is heavily structured. Further studies should test other materials, including the aspects of erosion. New construction materials with slippery coatings will offer new options in making buildings and other structures inaccessible to pigeons.

\section{Management implications}

Buildings can be protected effectively against feral pigeons by avoiding attractive structures during building design or by subsequent alterations of existing structures used by feral pigeons. Openings can be reduced to dimensions that pigeons are not able to pass. Ledges used by pigeons can be made unusable by increasing the angle of inclination according to building material properties. According to 
our experiment, we suggest to use the following pigeonsafe dimensions:

Pigeon-safe openings

Restriction in width $4 \mathrm{~cm}$

Restriction in height $5 \mathrm{~cm}$

Square restriction $6 \times 6 \mathrm{~cm}$

Pigeon-safe ledges

Ledge width $4 \mathrm{~cm}$

Smooth material (tinplate, glass, plastics) angle of inclination $25^{\circ}$

Medium rough material (wood, plane concrete) angle of inclination $35^{\circ}$

Rough material (sandstone, rough concrete) angle of inclination $50^{\circ}$

Acknowledgments We are very grateful to Andreas Ochsenbein for technical support and assistance. We thank Chris Feare for his valuable comments and amendments.

All experiments were performed with the animal experimental permission of the Cantonal Veterinary Office of Basel-Town, Switzerland (authorization no. 2121 of the 16 Feb. 2006) and conformed to Swiss law on animal welfare.

\section{References}

Andelt WF, Burnham KP (1993) Effectiveness of nylon lines for deterring Rock Doves from landing on ledges. Wildl Soc Bull 21:451-456

Carle R (1959) Die Vorbereitung zur Bestandsregelung unter den verwilderten Haustauben in den Städten. Städtehygiene 8:164-168

Del Monte M, Sabbioni C (1986) Chemical and biological weathering of an historical building: Reggio Emilia Cathedral. Sci Total Environ 50:165-182

Dell'Omo A (1996) Il ruolo degli escrementi dei piccioni nella bioalterazione delle rocce. Tesina di Università degli Studi di Roma "La Sapienza", Facoltà di Scienze Matematiche, Fisiche e Naturali, Dipartimento di Biologia Animale e dell'Uomo
Fabricius E, Jansson AM (1963) Laboratory observations on the reproductive behaviour of the pigeon (Columba livia) during the pre-incubation phase of the breeding cycle. Anim Behav XI (4):534-547

Haag D (1984) Ein Beitrag zur Oekologie der Stadttaube. Dissertation, Phil. Nat. Faculty of the University of Basel, Verlag Medizinische Biologie, Basel, Switzerland

Haag D (1991a) Population density as a regulator of mortality among eggs and nestlings of feral pigeons (Columba livia domestica) in Basel, Switzerland. In: Proceedings of International Symposium of the Working Group on Granivorous Birds, INTECOL, Slupsk, Poland, Sept 14-17 1989, Warzawa: J. Pinowski, B. P. Kavanagh and W. Gorski, PWN-Polish Scientific Publishers, Warzawa: 21-31

Haag D (1991b) Ethogramm der Taube. Ruhr University, Bochum Published in the series "Orn-Projekt"

Haag-Wackernagel D (1995) Regulation of the street pigeon in Basel. Wildl Soc Bull 23(2):256-260

Haag-Wackernagel D (2000) Behavioural responses of the feral pigeon (Columbidae) to deterring systems. Folia Zoologica 49 (2):25-39

Haag-Wackernagel D (2005) Parasites from feral pigeons as a health hazard for humans. Ann Appl Biol 147:203-210

Haag-Wackernagel D (2006) Human diseases caused by feral pigeons. Advances in Vertebrate Pest Management 4:31-58

Haag-Wackernagel D, Moch H (2004) Health hazards posed by feral pigeons. J Inf 48(4):307-313

Johnston RF, Janiga M (1995) Feral Pigeons. Oxford University Press, Oxford

Kern WH (2007) Pigeons. Fact Sheet SS-WEC-117 (UW117) Department of Wildlife Ecology and Conservation, Florida Cooperative Extension Service, Institute of Food and Agricultural Sciences, University of Florida. http://edis.ifas.ufl.edu/UW117

Kösters J, Kaleta EF, Monreal G, Siegmann O (1991) Das Problem der Stadttauben. Deutsches Tierärzteblatt 4:272-276

Landesamt fur Arbeitsschutz, Gesundheitsschutz und Technische Sicherheit Berlin (2000). Massnahmen der Taubenvergrämung. Fachinfo 1/2000, http://www.hygieneinspektoren.de/download/ tauben.pdf

Murton RK, Thearle RJP, Thompson J (1972) Ecological studies of the feral pigeon Columba livia var. I. Population, breeding biology and methods of control. J Appl Ecol 9:835-874

Simms E (1979) The public life of the Street Pigeon. Hutchinson, London

Thurston P (1983) Bauen für Segler. Gartenbauamt der Stadt Zürich

Wormuth HJ (1994) Zum Problem der verwilderten Haustauben. Merkblatt des Robert von Ostertag-Instituts des Bundesgesundheitsamtes, Berlin, p 6 